18 InterAção

\title{
JUNHO DE 2013 E OS SINAIS DE UMA CRISE1
}

Augusto César Dall' Agnol²

José Renato Ferraz da Silveira ${ }^{3}$

\section{Resumo}

Este trabalho busca compreender quais foram as dinâmicas que permearam o movimento Vem pra Rua em junho de 2013. Entende-se, então, que houve uma crise de mediação política no Brasil e que os partidos políticos já não se constituiriam em entidades com credibilidade perante a sociedade. Neste sentido, utiliza-se aqui do método dedutivo e da revisão bibliográfica acerca de quatro questões que se correlacionam ao longo do artigo: i) junho de 2013; ii) tragédia da política; iii) poder, Estado e legitimidade e; iv) crise política e vulnerabilidade dos partidos, a fim de compreender o sentido de governabilidade, governança, legitimidade e credibilidade no contexto do movimento de junho de 2013. Por fim, conclui-se que houve catarse, ou seja, um enfraquecimento do ímpeto para a ação sem ter-se concluído o ato, ou tendose concluído apenas um ato que não chega a alterar fatores significativos.

Palavras-chave: Legitimidade. Governabilidade. Credibilidade. Junho de 2013.

\begin{abstract}
This paper aims to discuss which were the dynamics that permeated the "Vem pra Rua" protests in June 2013. We understand that there was a crisis of political mediation in Brazil and that the political parties are no longer entities with credibility towards society. In this way, we use here the deductive approach and literature review about four topics that are correlated throughout the paper: i) June 2013; ii) tragedy of politics; iii) power, State and legitimacy and; iv) political crisis and the vulnerability of the political parties, in order to understand the meaning of governability, governance, legitimacy and credibility in the context of June 2013. Finally, we conclude that there
\end{abstract}

\footnotetext{
${ }^{1}$ As ideias centrais do presente trabalho foram apresentadas no I Seminário Internacional de Ciência Política, realizado pela Universidade Federal do Rio Grande do Sul (UFRGS), entre os dias 09 e 11 de setembro de 2015, no município de Porto Alegre - RS.

2 E-mail: a.agnol@gmail.com; CV Lattes: <http://lattes.cnpq.br/199548041655248>.

${ }^{3}$ E-mail: jreferraz@hotmail.com; CV Lattes: <http://lattes.cnpq.br/4118982709248739>.
} 
19 | InterAção

was catharsis, in other words, a decline of the impetus to the actions without having completed the act, or having been concluded only an act that does not change significant factors.

Key words: Legitimacy. Governability. Credibility. June 2013

\section{INTRODUÇÃO}

A vida humana é um caleidoscópio de emoções, sentimentos, desejos, intenções e projetos de vida. Muitos momentos se caracterizam por recomeços. Assim, a crise pode ser vista como um recomeço de um ponto que ainda não se encerrou. Um ponto que inicia, um fim que não se encerra. A crise é acompanhada pelo imponderável e a ruptura do início e do fim. É um possível recomeço.

Bobbio (1998, p. 305), por sua vez, entende o conceito de crise como um momento de ruptura no funcionamento de um sistema. Ou seja, todo o sistema se funda em "um conjunto de relações mais ou menos estreitamente coligadas entre os vários componentes, de tal forma que a mudança num dos componentes do sistema gera mudanças em todos os outros componentes". O que torna o presente estudo relevante é o fato de que, "enquanto nos sistemas mecânicos é possível avaliar cuidadosamente o efeito e a amplitude de semelhantes variações e até medi-las, no âmbito dos sistemas sociais se está ainda longe disso" (BOBBIO, 1998, P. 305). O estudo do momento de crise no sistema social brasileiro é o objeto que procura ser aqui estudado, ainda que o assunto esteja longe de ser esgotado.

O que entendemos por crise, então, seria o oposto à rotina, ou seja, não há previsibilidade para alianças, pautas e a confiança encontra-se em xeque. Em geral, o elemento determinante da Crise de Governo a qual Bobbio (1998, p. 
20 InterAção

304) se refere, se acha a nível das relações entre classe política e sociedade e pode depender "da falta de representatividade da classe política no poder [...] da falta de legitimação do sistema que é rejeitado por fortes grupos da comunidade e pela falta de eficácia em responder aos questionamentos da comunidade". É sobre essa Crise de Governo que o presente trabalho pretende se debruçar.

Antes de se iniciar a exposição das ideias deste trabalho, faz-se necessário ressaltar que o mesmo não tem como objetivo abordar a crise política que se instaura no período subsequente às manifestações de junho de 2013. Ou seja, a intrincada corrida eleitoral que ocorre ao longo do ano de 2014 e os protestos de março e agosto de 2015 não são nosso objeto de análise, ainda que as ideias centrais de tragédia e de crise política possam ser aplicadas também a estes casos. Temas como a Operação Lava Jato, Impeachment e Petrobrás não serão analisados neste artigo, por exceder o recorte temporal proposto inicialmente, cabendo a este estudar, ainda que propedeuticamente, as marchas de Junho de 2013 que antecederam a Copa das Confederações.

Do ponto de vista metodológico, o presente trabalho utiliza-se do método dedutivo. Optou-se por realizar uma revisão bibliográfica acerca do tema, sendo os principais autores divididos em quatro grupos que dialogam entre si: i) Singer (2013), Souza e Souza (2013) trazem informações relevantes quanto ao que estava acontecendo no momento em que se inicia o movimento "Vem pra rua"; ii) Silveira (2012) e Rinesi (2009) colaboram com o pensamento intrínseco da tragédia na política, ideia que é retomada ao longo do artigo; c) Tocqueville (2011), Deutsch (1983) e Bobbio (1998; 2010) colaboram com questões atreladas diretamente ao poder, Estado e legitimidade e, por fim, d) Baquero (2010) contribui com uma visão contemporânea a respeito da crise política e da vulnerabilidade dos partidos na América Latina. 
21 InterAção

\section{BRASIL, A CRISE E A TRÁGÉDIA DA POLÍTICA}

A política contemporânea é marcada pelo conflito em uma dimensão essencial. A teoria da tragédia da política pensa a vida, atividades, linguagens e as retóricas da política que apontam para a persistência das tensões tanto no cotidiano quanto na política, pois na vida e na sociedade os conflitos são agônicos. De acordo com Silveira (2012), a imprevisibilidade e o descontrole fazem parte das conjunturas políticas e, também, da existência. A teoria da tragédia da política nos mostra dois aspectos: qualquer sujeito que age em busca do poder político é introduzido em um embate, tendo, de um lado, o desejo e a determinação humana e, de outro, um processo baseado na Razão de Estado, portador de uma lógica própria e imperiosa.

Os protestos de Junho de 2013 são fenômenos que despertam a atenção na história do Brasil pós-redemocratização. Aqui, sustenta-se que este desgastante embate no qual estão envolvidos governantes e governados revelase próprio do processo democrático, seja no Brasil ou em outra parte do mundo. Há, neste sentido, uma crise de mediação política no Brasil e os partidos já não se constituem em entidades com credibilidade perante a sociedade. Snyder e Mansfiel (1995) definem a democratização como uma situação de mudança

social, de fraqueza institucional e de conflito de interesses. É o que se observa no Brasil. Assim, há um impasse político causado por maior abertura política, interesses inflexíveis, mobilização em massa pelas elites que competem a fraqueza do governo central.

Atualmente, como atesta Rodrigo Silva (2011, p. 36), "há uma crescente descrença das opiniões públicas quanto ao funcionamento real da vida 
22 | InterAção

democrática, cuja governança se tornou gestionária e é ditada pelo sensacionalismo midiático". Concomitantemente ao desgaste dos partidos e do movimento nas ruas, assistiu-se a emergência das redes sociais. Neste sentido, as redes passam a ser uma via em que as pessoas procuram manifestar anseios e frustrações, uma vez que o sistema político há anos deixou de conseguir os canalizar. O movimento relativizava o sensacionalismo midiático, ainda que em diferentes níveis. A grande mídia procurou desqualificar e criminalizar o movimento em um primeiro momento, entretanto as manifestações cresceram apesar da contrapropaganda da imprensa. Após inicialmente chamar os manifestantes de vândalos e baderneiros, a mídia resolveu fazer uma virada espetacular de opinião e passou, então, a apoiá-los (MOREIRA; SANTIAGO, 2013, p. 17).

A informação torna-se, cada vez mais, uma forma de conhecimento. Em um cenário em que os dois pólos de forças - as ações humanas e as dinâmicas autônomas do poder - estão presentes, e também na qual a representação política perpassa pela produção simbólica, o que imprime novos sentidos e significados às ações dos governantes, dos cidadãos ou grupos, e da mídia - em suas diferentes fontes - desempenha um papel fundamental na sociedade.

O impacto dos meios de comunicação de massa no cotidiano dos indivíduos nas diferentes modalidades da produção, disseminação e consumo intensifica a "espiral de desilusão e angústia" na opinião pública. Relacionar política a golpes baixos, a interesses particulares e egoísticos, à atração irresistível pelo poder, são pensamentos que se generalizam e fortalecem ao passo que um novo escândalo de corrupção é noticiado.

Esse ambiente político democrático é construído, portanto, a partir de rupturas - intensas e constantes - e há uma busca de uma "ordem mínima" de 
23 | InterAção

governabilidade ${ }^{4}$. Não há solidez na governança ${ }^{5}$ e, dessa forma, as iniciativas de sustentação política estão à "beira do abismo", em um equilíbrio delicado que raramente é atingido e mantido. Sem autoridade e governabilidade, os riscos e ameaças à ordem democrática se avolumam, uma vez que a governabilidade

exprime a margem de liberdade ou a capacidade de ação de que um governante dispõe, - em um determinado espaço nacional, em um determinado ciclo do processo de gestão -, para exercer seu mandato e realizar suas metas políticas atuando sob e sobre condicionantes de caráter histórico-estrutural e conjuntural existentes (YAMAUTI, 2004, p. 251).

Percebemos também a presença imanente da catarse ${ }^{6}$. Conforme Kaplan e Lasswell (1979, p. 36), "a probabilidade da catarse varia em proporção direta ao alcance do conflito e inversamente com a intensidade da situação". Ainda de acordo com Kaplan e Lasswell (1979, p.36-37)

a catarse é tanto mais provável quanto mais ela for facilitada por uma interferência com ações projetadas, e quanto menor for a intensidade destes atos na situação. Um movimento de protesto tem maior probabilidade de ceder sem atingir a sua meta quando há, i) interferência máxima com esta meta, da qual são indícios o aprisionamento dos líderes, a convocação de tropas, os apelos repetidos a símbolos de lealdade; e ii) intensidade inicial mínima, demonstrada pela falta de assiduidade nas manifestações e nas contribuições, pelo uso limitado de símbolos de protesto, e pela alta rotatividade dos membros (em situações de intensidade inicialmente elevada, a interferência pode ter o efeito de aumentar mais ainda a

\footnotetext{
${ }^{4}$ Entende-se aqui que a governabilidade diz respeito às "condições sistêmicas e institucionais sob as quais se dá 0 exercício do poder, tais como as características do sistema político, a forma de governo, as relações entre os Poderes, o sistema de intermediação de interesses" (Santos, 1997, p. 342). Ou seja, a governabilidade refere-se ao conjunto de condições necessárias ao exercício do poder.

${ }^{5}$ De acordo com Santos (1997, p. 341) a governança refere-se a "padrões de articulação e cooperação entre atores sociais e políticos e arranjos institucionais que coordenam e regulam transações dentro e através das fronteiras do sistema econômico". Neste sentido, governança é a competência do governo de praticar as decisões tomadas ou, em outras palavras, a capacidade de governo do Estado. Diz respeito, então, ao modo de operação do poder, à articulação entre atores, ao exercício da autoridade política e moral, ao desempenho das políticas públicas e às relações de sustentabilidade política e social de apoio aos governantes.

${ }^{6}$ De acordo com Kaplan e Laswell (1979), a catarse é uma resposta substitutiva frequentemente realizada através de uma cerimonialização ou de uma agressão dirigida contra um bode expiatório.
} 
24 InterAção

intensidade, ao invés de facilitar a catarse). Aqueles contra os quais se dirige o movimento de protesto, facilitam ainda mais a catarse ao fornecerem canais de reação substitutiva: pão e circo, símbolos de aquiescência que salvem a situação, alvos alternativos. A catarse controlada é um importante meio de controle político.

Algumas manifestações políticas acabam desaparecendo sem afetar a política de maneira permanente e, neste sentido, o movimento de junho de 2013 é visto como um ponto de inflexão acerca da crescente insatisfação e descontentamento no Brasil. A catarse, nesse caso, purificou de forma incompleta os espectadores que contemplam esse espetáculo trágico da política. Ainda, segundo Kaplan e Lasswell (1979, p. 36): "houve catarse: um enfraquecimento do ímpeto para a ação sem ter-se concluído o ato, ou tendo-se concluído apenas um ato que não chega a alterar fatores significativos".

Não há dúvida, em especial no contexto político brasileiro, que a presença do que chamamos de tragédia na política caracteriza-se no dilema insolúvel entre o possível e o desejável. Há uma forte tendência de elementos centrípetos - convergência - e centrífugos - divergência. Como afirma Rinesi (2009, p. 17):

O pensamento trágico, com efeito, na medida em que é um pensamento capaz de conviver com o conflito e de tentar pensar nele e a partir dele - e não apesar dele, nem muito menos contra ele -, na medida em que tende a ver os seres humanos dominados pela contradição, por cortes e desdobramentos, pelas exigências contrárias de requerimentos incompatíveis.

Em suma, podemos supor que é um otimismo irresponsável admitir que os conflitos na política são solucionáveis. A democracia tem na sua essência a perenidade do conflito e a consequente busca da conciliação de interesses divergentes. 
25 | InterAção

Assim, o conceito de "política como tragédia" - central nesse artigo aponta para a insuficiência das práticas políticas e clarifica que o governante ou o governo não tem controle absoluto de suas ações. Como atesta Karl Deutsch (1983, p. 23): “a política tornou-se, literalmente, um caso de vida ou de morte".

Neste sentido, o Brasil está passando pelo que pode ser um momento decisivo em sua formação nacional. São tempos de desorientação e incertezas que não são absolutamente negativos. Trata-se de uma espécie de "crise no sentido gramsciano, ou seja, em que o novo, que chega com vigor, ainda não acabou de nascer e o velho ainda não morreu de todo" (LAMPREIA, 1999, p. 59). Os cidadãos brasileiros buscam descobrir os seus próprios caminhos através do árduo caminho que leva à democracia. São tempos turbulentos.

Concordamos com Singer (2013, p. 24) e não adotaremos neste trabalho o termo “Jornadas de Junho" ${ }^{7 "}$, uma vez que

O junho brasileiro também produziu um tremor de terra, porém não chegaria a qualificá-lo de terremoto, uma vez que o travejamento fundamental da ordem não foi questionado. As relações de classe e propriedade não estiveram diretamente no centro das manifestações e as regras do jogo político foram visadas de maneira difusa.

\section{MOVIMENTO OU JORNADA? TOCQUEVILLE E O MOVIMENTO “VEM PRA RUA"}

O livro de Alexis de Tocqueville, Lembranças de 1848: as jornadas revolucionárias em Paris, contém passagens que demonstram que não é novidade

\footnotetext{
${ }^{7}$ As jornadas originais constam de 018 Brumário de Luís Bonaparte. Apesar da derrota armada, Marx (2011, p. 35) empenha-se em registrar que os insurretos sucumbiram com todas as honras, tendo feito a Europa tremer "frente ao terremoto de junho".
} 
26 | InterAção

o que se passa no Brasil. Ao descrever o declínio dos parlamentares da situação, Tocqueville (2011, p. 70) escreve que

de meu banco, observava essa multidão ondulante; percebia a surpresa, a cólera, o medo e a cupidez, perturbados, antes de ser saciados, misturarem seus traços naquelas fisionomias desorientadas; comparava, com meus botões, todos esses legisladores a uma matilha de cães da qual se arranca a carne ainda não devorada.

Mas não era somente à situação que Tocqueville (2011, p. 70) tecia suas críticas. A respeito da oposição da época, o autor escreveu que

de resto, é preciso reconhecer que um grande número de membros da oposição teria dado o mesmo espetáculo, se fosse submetido à mesma prova. Se muitos conservadores só defendiam o ministério com vistas a manter emolumentos e cargos, devo dizer que, a meu ver, muitos membros da oposição só o atacavam para conquistá-los.

Quanto ao terceiro grupo descrito - os descrentes - Tocqueville expressava claramente que a representação política não poderia, jamais, ser trocada em função da movimentação das ruas. Estas, é claro, deveriam ser sempre vistas como a tradução dos desígnios do que os cidadãos almejam. Ou seja, não se pode fazer política brigando nas ruas, sem haver uma instituição que garanta a eficácia e a legitimidade da luta, afinal, não pode haver representação adequada sem partidos $^{8}$ que canalizem a defesa dos interesses dos indivíduos.

\footnotetext{
${ }^{8} \mathrm{~A}$ ideia de partido político que se concebe aqui vai ao encontro do conceito disponível no Dicionário de Política de Bobbio (1998, p. 898-899). "Segundo a famosa definição de Weber, o Partido político é "uma associação... que visa a um fim deliberado, seja ele 'objetivo' como a realização de um plano com intuitos materiais ou ideais, seja 'pessoal', isto é, destinado a obter benefícios, poder e, conseqüentemente, glória para os chefes e sequazes, ou então voltado para todos esses objetivos conjuntamente". Esta definição põe em relevo o caráter associativo do partido, a natureza da sua ação essencialmente orientada à conquista do poder político dentro de uma comunidade, e a multiplicidade de estímulos e motivações que levam a uma ação política associada, concretamente à consecução de fins "objetivos" e/ou "pessoais"".
} 
27 InterAção

Alexis de Tocqueville não era avesso às mudanças, entretanto não acreditava na convulsão revolucionária como meio de ação, e é por isso que Norberto Bobbio o classifica como um liberal conservador. Se o Legislativo da França estava desprestigiado, assim como está o nosso atualmente, Tocqueville pensava que o mesmo deveria ser preservado em detrimento dos revolucionários que desejavam pura e simples abolição das instituições. Ou seja, confiar nas revoluções não era uma boa alternativa, segundo o autor, afinal, elas obedecem a uma dinâmica irracional e terminam beneficiando os oportunistas e sacrificando a maioria. É importante sublinhar a diferença entre extremismo e moderação, que segundo Deutsch (1983, p. 28), “depende da capacidade de reconhecer a realidade e de analisar a veracidade das opiniões. $\mathrm{O}$ extremismo implica sempre uma tendência para auto decepção, indiferentes às virtudes da causa que é suposto servir".

Na atual situação, é difícil que possamos contemplar algo a meio caminho entre situação e oposição. O que confere atualidade dos escritos de Tocqueville é, por exemplo, a aplicação das suas "Lembranças de 1848" a nossa crise. Mas não somente a esta crise. Às crises que vêm desde as disputas do Partido Liberal e do Partido Conservador - do Brasil Império -, e que continuarão existindo a nível nacional, estadual ou municipal. Como afirma o autor

a verdade, deplorável verdade, é que o gosto pelas funções públicas e o desejo de viver à custa dos impostos não são, entre nós, uma doença particular de um partido: é a grande e permanente enfermidade democrática da nossa sociedade civil e da centralização excessiva de nosso governo; é esse mal secreto que corroeu todos os antigos poderes e corroerá igualmente todos os novos (TOCQUEVILLE, 2011, p. 70). 
28 InterAção

O nosso destino encontra-se, então, dependente de decisões e políticas em implementação ou em maturação e de uma vitória decisiva do novo sobre o velho. Como afirma Lampreia (1999, p. 60)

foi o caso da Espanha de Carlos V, da França de Luís XIV, da Grã-Bretanha no final do século XVIII e início do século XIX e dos Estados Unidos no final do século XIX até o New Deal de Roosevelt - duas ou três décadas de transformações e consolidação que forjaram a personalidade interna (política, econômica e social) e internacional (diplomática e estratégica) desses países e lhes deram traços duradouros como nações e como forças dominantes nas relações internacionais em seus respectivos períodos de apogeu.

\section{MOVIMENTOS DE JUNHO E A CRISE POLÍTICA NO BRASIL}

De acordo com Singer (2013, p. 24-26), os acontecimentos de 2013 dividiram-se em três fases. "A ebulição foi iniciada por fração pequena, embora valorosa, da classe média, com mobilizações praticamente circunscritas à cidade de São Paulo nos dias 6, 10, 11 e 13 de junho" (SINGER, 2013, p. 24). Nessa primeira etapa havia um objetivo específico: a redução do preço das passagens do transporte público. Inicia-se, então, a segunda etapa do movimento, com as manifestações de 17, 18, 19 e 20 de junho, quando alcança o seu auge. "Agora outras frações da sociedade entram espontaneamente em cena, multiplicando por mil a potência dos protestos, mas simultaneamente tornando vagas as suas demandas" (SINGER, 2013, p. 25).

De milhares, as contas de gente na rua passam a centenas de milhares. Quando o Movimento Passe Livre chama a quarta jornada, que juntou em São Paulo 75 mil pessoas, ela é replicada nas maiores capitais do país da maneira espontânea. A depredação de edifícios públicos (Assembleia Legislativa do Rio 
29 | InterAção

de Janeiro, Congresso Nacional, Itamaraty) "pareceu ser expressão de um clima de repúdio aos políticos em conjunto" (SINGER, 2013, p. 25). Com o início da Copa das Confederações, em 16 de junho, São Paulo perde centralidade, com o protagonismo passando às praças onde haveria jogos: Brasília, Fortaleza, Salvador, Belo Horizonte e Rio de Janeiro.

Na terceira e última etapa, que vai do dia 21 até o final do mês, o movimento se fragmenta em mobilizações parciais com objetivos específicos redução de pedágios, derrubada da PEC 379, protesto contra o Programa Mais Médicos ${ }^{10}$. Ainda sob o impulso da força liberada na segunda fase, mas já separadas por inclinações diferentes, "as manifestações começam a se dividir, como um rio que se abrisse em múltiplos braços no descenso da montanha" (SINGER, 2013, p. 26).

Ao se observar as bandeiras, cartazes e palavras de ordem que estavam nas ruas depreende-se que havia uma diversidade de sujeitos anônimos, desconhecidos, pelo menos na cena política convencional. Parece ser evidente, com isso, que há uma crise no sistema político brasileiro, "o qual apresenta várias fragilidades e fissuras políticas que impedem mudanças mais significativas, capazes de pôr fim a determinadas questões presentes na sociedade brasileira, a exemplo da corrupção" (MOREIRA; SANTIAGO, 2013, p. 17)

Como afirma Marilena Chauí (2013, p. 01)

faz mais sentido defender a ética da política, porque se há boa qualidade das instituições, não vai poder haver corrupção, pois a corrupção decorre das péssimas qualidades das nossas

\footnotetext{
${ }^{9}$ A PEC 37 sugeria incluir um novo parágrafo ao Artigo 144 da Constituição Federal, que trata da Segurança Pública. 0 item adicional traria a seguinte redação: "A apuração das infrações penais de que tratam os $\S \S 1^{\circ} \mathrm{e} 4^{\circ}$ deste artigo, incumbem privativamente às polícias federal e civis dos Estados e do Distrito Federal, respectivamente".

100 Programa Mais Médicos (PMM) é parte de um amplo esforço do Governo Federal, com apoio de estados e municípios, para a melhoria do atendimento aos usuários do Sistema Único de Saúde (SUS).
} 
30 InterAção

instituições, que não são verdadeiramente republicanas nem verdadeiramente democráticas.

Norberto Bobbio (2010, p. 24) apresenta, neste contexto, três traços relevantes da democracia.

a característica do regime democrático, nesse aspecto, é o princípio eletivo: a classe política, em regime democrático, tira a justificação do seu poder da eleição popular. [...] O segundo aspecto da democracia liga-se ao primeiro e o integra. Para que se possa falar de democracia, não basta que a classe política seja eleita, em outras palavras, que seu poder seja fundado num consenso inicial originário. É necessário que esse consenso seja periodicamente repetido. Não basta o consenso, mas é necessária uma verificação periódica do consenso. Uma classe política que tivesse derivado seu poder de uma eleição inicial, e depois não fosse submetida a nenhum controle ulterior, levaria a um regime que não se poderia chamar democrático."

Neste sentido, o apartidarismo observado no movimento "Vem pra rua" pode indicar dois possíveis caminhos: i) negação ao sistema partidário atual e ii) ao desencanto com a democracia representativa. Ao discorrer acerca das manifestações de junho de 2013, por exemplo, Ruy Braga (2013, p. 58) sinaliza que "a atual onda de mobilizações significou a retomada da luta do proletariado precarizado brasileiro por seus direitos sociais". Em agosto de 2015, novas manifestações ocorrem nas capitais e maiores cidades do Brasil e, com isso, começamos a perceber alguns pontos que merecem ser sinalizados. Muito do que foi escrito no irromper das manifestações foram comentários e diagnósticos enviesados e carregados de sentimentos passionais. Que as manifestações de 2013 causavam incertezas, não restam dúvidas. Não tinham uma liderança e nem uma única causa. Mas uma constatação é clara: podemos negativar a frase de Braga. Ou seja, as manifestações que se iniciam em 2013 são qualquer coisa, menos uma retomada da luta do proletariado brasileiro por seus direitos sociais. 
31 InterAção

Marcello Baquero (2000, p. 7), ainda no início do milênio aponta que "noticiários, pesquisas de opinião e os estudos de caráter acadêmico, diariamente, nos mostram o desencanto dos cidadãos com a política e com os políticos". O autor defende, ainda, que "não há indícios de que esse processo crescente de descontentamento e desilusão institucional será superado a curto prazo". É neste contexto que ocorreram os protestos - e a sua característica apartidária, e por vezes antipartidária - de junho de 2013.

Ainda de acordo com Baquero (2000, p. 8), quando o tema é crise de mediação política que tem como a crise dos partidos no centro do debate, sua compreensão e superação passa por "um entendimento dos vários fatores que nela incidem, entre os quais o legado histórico, a forma como se estruturaram essas organizações, o seu relacionamento com a sociedade civil e as suas dificuldades na tarefa de mediação política".

Concorda-se, aqui, com a ideia que a descrença nos partidos faz parte de um processo de construção de cultura política, na qual as rupturas institucionais geram grau zero na política, apagando o passado e criando expectativas sobre o futuro (BAQUERO, 2000). Neste sentido, Paz (1991, p. 17)

à medida que eles [os partidos políticos] esboçam sinais de debilidade, são extintos no propósito de recriá-los fortes e imaculados. Obviamente, tal processo não inclui instituições como o Estado e as Forças Armadas, mas sim os partidos políticos.

Baquero (2000, p. 147) aponta, ainda, que essa situação "faz com que o personalismo se institucionalize como fator estrutural, e a falta de compreensão desse fator pode gerar distorções na análise da eficiência dos partidos num sistema político". Neste sentido, Yamauti (2004, p. 259) aponta que "devido ao forte personalismo configurado pelo sistema político, um único indivíduo será apontado, indevidamente, como o responsável por todas as desgraças da 
32 | InterAção

nação". Procura-se um responsável, e ao processo descrito acima, com base nos argumentos dos autores, chamamos de imputação, que concatena com a ideia de grau zero, de catarse e da ideia da crise gramsciana, no sentido de nascer o novo sobre o velho.

A crise de representatividade, então, faz parte do processo de democratização política, e as maneiras de superá-la envolvem, inclusive, as possibilidades de apagar o passado indesejado e criar expectativas sobre um futuro incerto. Os movimentos de Junho de 2013 são aqui enquadrados dentro desta perspectiva. Ou seja, apesar de ter havido heterogeneidade nos pleitos, havia uma pauta comum que giraria em torno de saúde, educação, combate a corrupção e mobilidade urbana, tudo em contraste com a realização da Copa do Mundo. Acredita-se, entretanto, que isso sempre foi pauta comum. Raramente foi visto um partido ou um político ser contra essas demandas. Talvez o que se gritasse nas ruas era justamente a exigência de haver seriedade no tratamento destas questões. Afinal, sempre se falou delas, mas elas nunca, ou dificilmente, funcionaram. Diante disso, as relações entre sociedade e partidos políticos atuais - e isso envolve situação e oposição - não conseguem suprir os anseios populares. Este talvez seja o motivo das manifestações terem sido apartidárias, no sentido de não ter um partido na liderança das mesmas, e em breves momentos anti partidárias, no sentido de não desejarem um partido que reunisse os seus anseios.

Percebe-se, assim, que houve um descompasso crescente entre a agenda do governo e os anseios da sociedade civil, ainda que estes fossem difusos. $\mathrm{O}$ problema deflagrou-se, então, com as questões do transporte público e da Copa das Confederações e a sensação de que muito foi investido em áreas não essenciais. Enquanto isso, as agendas brasileiras permaneceram paradas. A 
33 | InterAção

sociedade exiga agendas maiores e mais significativas para o país, e é isso que estava sendo transmitido das redes sociais para as ruas.

Bobbio (1998, p. 676), ao definir o conceito de legitimidade, aponta que é essencial distinguir o poder legal e o tradicional do poder pessoal ou carismático - esta célebre tripartição é de Max Weber. A legitimidade do primeiro tipo de poder tem seu fundamento na crença de que "são legais as normas do regime, estabelecidas propositalmente e de maneira racional, e que legal também é o direito de comando dos que detêm o poder com base nas mesmas normas". A legitimidade tradicional, por sua vez, "assenta no respeito às instituições consagradas pela tradição e à pessoa ou às pessoas que detêm o poder, cujo direito de comando é conferido pela tradição". Por fim, a legitimidade carismática do terceiro tipo tem

seus alicerces substancialmente nas qualidades pessoais do chefe e, somente de forma secundária, nas instituições. Este tipo de legitimidade, pela sua ligação com a pessoa do chefe, tem existência efêmera, por não resolver o problema fundamental para a continuidade das instituições políticas, isto é, o problema da transmissão do poder.

Compreende-se, neste trabalho, portanto, que não houve uma crise de legitimidade no sentindo da tripartite proposta por Weber no "Movimento Vem pra Rua". Houve uma crise de credibilidade para com a classe política. Neste sentido, convém assinalar que o regime democrático prevê que as decisões políticas sejam tomadas tendo por critério a vontade da maioria, o que no caso brasileiro é filtrado pelo instituto da representação política através das instituições. O governo Rousseff estava longe de ter na Presidente uma personagem carismática - e a sua legitimidade não decorria de seu carisma ainda em 2013, principalmente quando comparada ao seu antecessor. O que se depreende, neste sentido, é que a depredação do Itamaraty, das Prefeituras de Porto Alegre e Rio de Janeiro, bem como a invasão ao Congresso Nacional 
34 | InterAção

representam a insatisfação da sociedade para com as instituições que as representam. Mas estes atos não foram suficientes para que tivéssemos uma crise de legitimidade tradicional. Houve questionamento e ataques a algumas instituições, ou seja, ouve um tremor de terra, mas não um terremoto, que caracterizaria uma verdadeira crise de legitimidade. Além disso, as críticas - e por vezes insultos - à Presidente também marcaram os protestos de junho de 2013. Em suma, descarta-se a chance da legitimidade da representação popular basear-se no carisma de um ícone político carismático e, por fim, ainda que tenham existido tais manifestações contrárias aos representantes políticos e às instituições, não percebemos em junho de 2013 uma crise de legitimidade, o que, dois anos depois, não é descartável por completo. Conforme Marcelo Suano (APUD PINHEIRO, 2015), a respeito das manifestações de agosto de 2015 ,

o Brasil não está caminhando para um entendimento e muito menos para um pedido de desculpa, pacto ou coalizão de lideranças. Ele caminha para a ruptura e para brigas internas dentro do governo. Cada horas as alianças estão mudando de lugar, gerando mais crise, insatisfação e perda de credibilidade.

De acordo com Baquero (2000, p. 149) de maneira geral, as relações Estado e sociedade civil via constituições, leis, decretos e outros atos administrativos se caracterizam pela incerteza dos cidadãos. Isso fica evidente nos protestos de 2013 com a atuação do deputado Feliciano (PSC-SP) na Comissão de Direitos Humanos da Câmara dos Deputados, a Proposta de Emenda Constitucional 37, vetando a possibilidade de o Ministério Público fazer investigações independentes, o voto distrital e o repúdio aos partidos.

Como atesta Singer (2013, p. 26), surge quase um cartaz por manifestante, o que leva a uma profusão de dizeres e pautas, como 
35 | InterAção

"Copa do Mundo eu abro mão, quero dinheiro pra saúde e educação", "Queremos hospitais padrão Fifa", "O gigante acordou", "Ia ixcrever augu legal, maix fautô edukssão", "Não é mole, não. Tem dinheiro pra estádio e cadê a educação", "Era um país muito engraçado, não tinha escola, só tinha estádio", "Todos contra a corrupção", "Fora Dilma! Fora Cabral! PT= Pilantragem e Traição", "Fora Alckmin", "Zé Dirceu, pode esperar, tua hora vai chegar", foram algumas das inúmeras frases vistas nas cartolinas.

Neste sentido, os movimentos de 2013 não se enquadram, ao nosso ver, dentro de uma crise de legitimidade no sentido proposto por Weber, ainda que possa ser encarada com um prenúncio - não necessariamente - para um crise de legitimidade posterior. Identifica-se, assim, uma crise nos partidos que produz um círculo vicioso, no qual as reivindicações da população não chegam ao Estado, criando uma situação em que a própria legitimidade do sistema pode ser colocada em dúvida (BAQUERO, 2000, p. 154). Entende-se que houve uma crise de governabilidade e se contestou os mecanismos de intermediação política e o próprio sistema político.

A crença, compartilhada por amplos setores políticos e sociais, de que os partidos políticos podiam - e deveriam - ser canais de enfrentamento da crise de legitimidade do regime, seja como instrumento de canalização de demandas político-sociais, seja em seu papel clássico de promover a mediação entre interesses e projetos políticos que então estavam em pauta (FREIRE, 2014, p. 308). Porém, apesar da refundação dos partidos como atores ativos na reconstrução democrática, como eixos de articulação política, eles não têm conseguido cristalizar as expectativas populares depositadas neles.

Por fim, conclui-se que a crise de participação poderá ser resolvida se aceitarmos a obsolescência dos sistemas partidários como oligopólio da oferta de participação. Assim, o problema da representação, de acordo com a ideia de 
36 | InterAção

Santos (1985), poderá ser resolvido mediante o alargamento do escopo das formas legítimas de participação.

\section{CONSIDERAÇÕES FINAIS}

As manifestações de 2013 constituem-se, então, como um momento inicial para as que se seguem ao longo do ano de 2014 e, principalmente, de 2015. A perplexidade dos representantes político institucionais frente aos acontecimentos de junho de 2013 é um aspecto instigante para análise. A constatação é que os movimentos revelaram os vários limites da política formal. De acordo com Moreira e Santiago (2013, p. 14), os protestos ocorridos em junho "levaram às ruas centenas de pessoas e agrupamentos políticos, tendo como principal característica a participação de cidadãos e cidadãs não inseridos nos tradicionais movimentos sociais". Tivemos, assim, a presença marcante da juventude, estudantes universitários e secundaristas. As reivindicações escritas em cartazes eram bastante difusas, desde protestos contra corrupção, melhoria na qualidade dos serviços públicos, críticas contra os estádios da Copa e das Olimpíadas.

Compreende-se aqui movimento de contestação sinalizou um sentimento de "ruptura" e de descontentamento com a política atual brasileira. "A tragédia da ação política consiste em que sempre resta algo de ingovernável, de incontrolável, de incognoscível" (RINESI, 2009, p. 65). O caso brasileiro tem um

quê de inevitável e fora do comum. O sentimento de angústia, insatisfação generalizada em relação ao futuro, no movimento que surge em 2013 e que se reforçou no ano de 2015, muitas vezes escapa das possibilidades intelectuais de 
37 | InterAção

análise - razão e compreensão - e das capacidades de controle e gestão governamental.

Entre o reino do desejável e do possível é o universo trágico da política, principalmente em regimes democráticos jovens e em processo de maturação como o caso brasileiro. A crise parece sem solução, mas nossa democracia não pode ficar em xeque. Como uma tragédia, há muito indeterminismo, muitos atores em cena representando diversos e múltiplos papéis e como alude Shakespeare: um mundo acerca do qual não sabe nem pode pretender saber tudo. Como afirma Rinesi (2009, p.73-74), "esse não saber tudo" - ou não acreditar, nem poder, nem pretender saber tudo - sobre o mundo é a condição mesma da experiência do trágico e o traço definidor do que corresponderia chamar universo trágico".

\section{REFERÊNCIAS}

BAQUERO, Marcello. A vulnerabilidade dos partidos políticos e a crise da democracia na América Latina. Porto Alegre: Editora UFRGS, 2000.

BOBBIO, Norberto. Dicionário de política I. Brasília: Editora UnB, 1998.

BOBBIO, Norberto. Qual democracia? São Paulo: Editora Loyola, 2010.

DEUTSCH, Karl. Política e governo. Brasília: Editora UnB, 1983.

FREIRE, Américo. A via partidária da transição política brasileira. Varia história. n. 52, v. 30, p. 287-308, 2014.

LAMPREIA, Luiz Felipe. Diplomacia brasileira: palavras contextos e razões. Rio de Janeiro: Editora Lacerda, 1999.

LASSWELL, Harold Dwight; KAPLAN, Abraham. Poder e Sociedade. Brasília: UnB, 1979.

MARX, Karl. O 18 Brumário de Luís Bonaparte. São Paulo: Boitempo, 2011. 
38 InterAção

PAZ, Francisco M. Em torno da lógica da política: a cultura apartidária. Análise e conjuntura. Belo Horizonte, v. 6, n. 3, p. . 1991.

PINHEIRO, Augusto. Oposição endossa protestos de domingo pelo impeachment da presidente Dilma. RFI. 14 ago. 2015. Disponível em: <http://www.brasil.rfi.fr/brasil/20150814-oposicao-endossa-protestos-peloimpeachment-de-dilma>. Acesso em: 19 ago. 2015.

RINESI, Eduardo. Política e tragédia: Hamlet, entre Hobbes e Maquiavel. Rio de Janeiro: Editora Beco do Azougue, 2009.

SANTOS, Maria Helena de Castro. Governabilidade, Governança e Democracia: Criação da Capacidade Governativa e Relações Executivo-Legislativo no Brasil Pós- Constituinte. Dados. Rio de Janeiro, v. 40, n. 3, p. 333-376, 1997.

SANTOS, Wanderley Guilherme dos. O século de Michels: competição oligopólica, lógica autoritária e transição na América Latina. Dados. v. 28, n. 3 , 1985.

SILVA, Rodrigo; NAZARÉ, Leonor (Orgs). A república por vir: arte, política e pensamento para o século XXI. Lisboa: Editora Calouste Gulbekian, 2011.

SILVEIRA, José Renato Ferraz da. A tragédia da política em Ricardo II. Rio de Janeiro: Beco do Azougue, 2012.

SINGER, André. Brasil, Junho de 2013: classes e ideologias cruzadas. Novos Estudos, Dossiê Mobilizações, protestos e revoluções, n. 97, 2013.

SNYDER, Jack; MANSFIELD, Edward D. Democratization and the Danger of War. International Security, n. 1, n. 20, p. 5-38, 1995.

SOUZA, Cidoval Morais de; SOUZA, Arão de Azevedo (Orgs.). Jornadas de junho: repercussões e leituras. [Livro eletrônico]. Campina Grande: EDUEPB, 2013. Disponível em: <http://www.uepb.edu.br/editora-universitariadisponibiliza-e-books-jornadas-de-junho-e-campina-grande-hoje-e-amanha/>. Acesso em: 13 ago. 2015.

TOCQUEVILLE, Alexis de. Lembranças de 1848: as jornadas revolucionárias em Paris. São Paulo: Editora Companhia das Letras, Penguin, 2011.

YAMAUTI, Nilson Nobuaki. Os riscos de uma crise de governabilidade no Brasil segundo uma concepção dialética da realidade social. Acta Scientiarum. Human and Social Sciences, Maringá, v. 26, n. 2, p. 251-264, 2004. 
39 | InterAção 